\title{
Adorno Leitor de KierkegaARd: OU, A ESTÉtica de CONTEÚdo CoMo HERANÇA MATERIALISTA
}

\author{
[ADORNO READER OF KIERKEGAARD: OR, THE AESTHETICS OF CONTENT AS MATERIALISTIC
} HERITAGE]

\section{Fábio Caires Correia * Centro Universitário Católica do Tocantins, Brasil}

\begin{abstract}
Resumo: Objetivamos neste texto (I) mostrar os elementos que constituem a critica de Kierkegaard a Hegel e (II) as implicações desta crítica para uma suposta virada estética realizada por Adorno em sua filosofia como possibilidade de superação da dialética hegeliana. A hipótese que levantaremos aqui é que na crítica à concepção do estético em Kierkegaard, Adorno percebe a possibilidade da construção de uma noção de experiência racional irrestrita que tornará possível a saída efetiva do idealismo especialmente por meio do que mais tarde ele chamará de estética materialista dialética (materialistischdialektischen Ästhetik). Buscaremos mostrar que ao movimentar o pensamento de Kierkegaard contra Hegel (e vice-versa), o que Adorno faz, além de reconstruir criticamente a ideia hegeliana de dialética, é promover a implosão do idealismo presente em ambos os autores. Em outros termos, ele realiza uma interpretação materialista da dialética que traz à consciência o caráter mediado (necessário) da experiência real e concreta do sujeito com o mundo, sem subtrair um polo no outro, i.e., uma dialética que visa à desintegração do modelo idealista da subjetividade constitutiva sem eliminar a subjetividade tampouco o seu polo oposto.
\end{abstract}

Palavras-Chave: Construção do estético; Kierkegaard; Hegel; Adorno; Experiência
Abstract: We intended in this paper (I) to show the elements that constitute Kierkegaard's critique of Hegel and (II) the implications of this criticism for a supposed aesthetic turn made by Adorno in his philosophy as a possibility to overcome the hegelian dialectic. The hypothesis that we will raise here is that in the criticism of Kierkegaard's conception of the aesthetic, Adorno realizes the possibility of building a notion of unrestricted rational experience that will make possible the effective exit of idealism, especially through what he will later call dialectical materialist aesthetics (materialistisch-dialektischen Ästhetik). We will try to show that when moving Kierkegaard's thought against Hegel (and vice-versa), what Adorno does, besides critically reconstructing the Hegelian idea of dialectics, is to promote the implosion of the idealism present in both authors. In other words, he performs a materialist interpretation of the dialectic that brings to consciousness the mediated (necessary) character of the subject's real and concrete experience with the world, without subtracting one pole from the other, i.e., a dialectic that aims at the disintegration of the idealistic model constitutive subjectivity without eliminating subjectivity nor its opposite pole.

KEYwORDS: Construction of the aesthetic; Kierkegaard; Hegel; Adorno; Experience

* Doutor em Filosofia pela Pontificia Universidade Católica do Rio Grande do Sul. Doutorado em Filosofia pela Pontifícia Universidade Católica do Rio Grande do Sul, Brasil(2020). Coordenador de Pesquisa e Extensão do Centro Universitário Católica do Tocantins. E-mail: fabio.correia@catolica-to.edu.br 


\section{INTRODUÇÃo}

\section{Meu caro Friedel,}

Hoje por fim cheguei a uma carta; depois de algumas semanas muito atribuladas estou de volta às minhas quatro paredes, não vejo ninguém fora os professores, trabalho e estudo a existência. Um piano, velho, mas utilizável, fica no meu quarto; a prateleira de livros está lá faz tempo, com muitos Kierkegaard, Lila vai ficar fora por um periodo indeterminado (no minimo seis semanas!), e assim é possivel viver, se quisermos. Eu estou constantemente triste, solitário, sem entusiasmo tanto no sentido vitoriano como no maldito sentido psicológico imanente, e tenho saudades de você, a quem agora, que seja sempre assim até que haja algum término, estou atado na morte e na vida (BUSSIUS, 2009, p. 25).

A s correspondências nos finais dos anos 20 com Alban Berg (1885-1935) e Siegfried Kracauer (1889-1966), nos permitem perceber, de maneira bastante significativa, o incipiente interesse de Adorno pela filosofia antiacademicista e existencial do dinamarquês Søren Aabye Kierkegaard (1813-1855). À époça, ela representava, por ser "a primeira critica histórica ao idealismo hegeliano" (GÓMEZ, 1998, p. 48), um modelo de pensamento extremamente sedutor. Segundo Perius (2011, p. 119), "o grande mérito de Kierkegaard foi ter localizado o momento da não-verdade que representa o individuo nos sistemas que pretendem identificá-lo imediatamente com o coletivo, com o universal". Nesse sentido, o movimento que aqui nos propomos a realizar é (I) justificar a tese indicada por Perius (2011), mostrando os elementos presentes na critica de Kierkegaard a Hegel - consequentemente o que a faz tão sedutora - e (II) demonstrar as implicações desta critica para uma suposta virada estética da filosofia realizada por Adorno como possibilidade de saída (ou abertura) da dialética hegeliana - tese amplamente defendida por Gómez (1998). A hipótese que nos orienta aqui é que na crítica à concepção do estético em Kierkegaard, Adorno percebe a possibilidade da construção de uma noção de experiência racional irrestrita que tornará possivel a saida efetiva do idealismo e, por isto, sua aproximação com o materialismo. Mostraremos que ao movimentar o pensamento de Kierkegaard contra Hegel (e viceversa), o que Adorno faz não é só reconstruir criticamente a ideia hegeliana de dialética, mas promover a implosão do idealismo presente em ambos os autores. Em outros termos, ele realiza uma interpretação materialista da dialética que traz à consciência o caráter mediado (necessário) da experiência real e concreta do sujeito com o mundo, sem subtrair um polo no outro, i.e., uma dialética que visa à desintegração do modelo idealista da subjetividade constitutiva sem eliminar a subjetividade tampouco o seu polo oposto.

\section{HEGEL E KIERKEGAARD: DESENTENDIMENTOS ACERCA DA DIALÉTICA}

Para Hippolyte, a Fenomenologia do espirito pode ser lida como "o desenvolvimento concreto e explícito da cultura do individuo, [i.e.,] a elevação de seu eu finito ao eu absoluto, mas essa elevação não é possivel senão ao utilizar os momentos da história do mundo que são imanentes a essa consciência individual" (HIPPOLYTE, 2003, p. 57). Esses momentos da história do mundo, representados pela ideia de um Eu que é desde o inicio uma estrutura social, passagem do finito ao absoluto, segundo Hippolyte, são bastante significativos para compreendermos o movimento do espirito dentro do sistema hegeliano. Esses momentos oscilam entre a) a emergência da consciência de si como sujeito do conhecimento (consciência); b) o sujeito da experiência moral (eticidade); c) o sujeito do vínculo político (direito) e, por fim, d) o 
conteúdo da arte (estética). Nesse sentido, o Eu, em Hegel, nunca é uma pura individualidade, mas, em seus próprios termos,

[n]o desvanecer do ser-aí imediato do que é conhecido como essência absoluta, o imediato recebe seu momento negativo; o espírito permanece [o] $\mathrm{Si}$ imediato da efetividade, mas como a consciência-de-si universal da comunidade; [consciênciade-si] que em sua própria substância repousa, assim como esta é sujeito universal na consciência-de-si. O que constitui o todo completo desse espírito não é o Singular [só], mas sim o Singular junto com a consciência da comunidade e o que ele é para a comunidade (HEGEL, 2003, p. 512).

A partir disso, a pretensão de certeza dos fundamentos, característica muito própria à lógica operativa da modernidade filosófica, indica que a totalidade do sistema hegeliano é orientada por uma concepção abrangente de razão. Em uma famosa sentença dos Grundlinien der Philosophie des Rechts, Hegel diz que "o que é racional (was vernünftig ist), isto é efetivo (ist wirklich) e o que é efetivo, isto é racional" (HEGEL, 2010, p. 41). Essa sentença indica

[m]ais do que uma apologia ao existente, [ela] remete ao fato de que a racionalidade não é simplesmente o que as pessoas pensam. Aqueles esquemas conceituais que estão meramente na cabeça de alguém não conhecem ainda a efetivação e são, portanto, uma manifestação totalmente abstrata da razão. O real, ao invés disso, é o próprio desdobramento e revelação da racionalidade ( $\_$).

O que está em questão aqui, desse modo, é precisamente um modelo de racionalidade que pretende ser ela mesma a dinâmica da própria realidade, isocronicamente, a realidade constitui a dinâmica efetiva da razão. É uma razão que pretende a identificação imediata entre lógica (logik) e realidade (Wirklichkeit), ou seja, uma reciprocidade imanente entre ambas estruturas. Com essa sentença Hegel pretende escapar i) de um modelo de racionalidade meramente subjetiva - a exemplo de Kant ou mesmo Fichte -, sem, no entanto, ii) recair num realismo objetivo - o que faria da razão subjetiva um mero reflexo de objetos (psicologismo). Pelo contrário, a suprassunção (Aufhebung) desse dualismo resulta clara a relação de imanência entre razão-realidade (Was vernünftig ist, das ist wirklich) em todos os seus momentos constitutivos. É por conta da necessidade do próprio movimento em direção à universalidade que se fez mister, para o autor alemão, superar a velha dicotomia sujeito-objeto, superar, in fine, o velho dualismo epistemológico kantiano (fenômeno e o noumeno). Há, na Enciclopédia, um excerto que caracteriza pontualmente o acima exposto. Diz Hegel:

[a] relação de formas tais como o conceito, o juízo, o silogismo, com outras formas como causalidade etc. só se pode demonstrar no interior da Lógica mesma. Mas previamente é preciso atentar bem que, enquanto o pensamento procura fazer das coisas um conceito, esse conceito (e por isso também suas formas mais imediatas, o juizo e o silogismo) não pode consistir em determinações e relações que sejam estranhas e exteriores às coisas. A reflexão [...] leva ao universal das coisas; esse porém é, ele mesmo, um dos momentos-do-conceito. Que haja entendimento e razão no mundo, isso diz o mesmo que contém a expressão "pensamento objetivo". Mas essa expressão é incômoda, justamente porque "pensamento" é usado com demasiada frequência só como [significando] o que pertence ao espírito, à consciência; e também o "objetivo" é usado, antes de tudo, [a propósito] do não-espiritual (HEGEL, 1995, p.77).

$\mathrm{Na}$ representação intelectiva da realidade em seu processo dinâmico de efetivação, em que a dialética se mostra como uma força extraordinariamente vital resta algo fundamental, dirá Kierkegaard, a saber, a consideração da realidade singular do indivíduo como dado primário e irredutivel. Para o filósofo dinamarquês, 
existência para suprimir o dilema. É impossível realizar isso na existência, porque estaria anulando também a existência. Se seu deixar de lado a existência (se dela fizer uma abstração), não há ou/ou, se eu deixar de lado a existência, isto significa que deixo de lado a existência, mas nesse caso não a anularei na existência. Se é incorreto que haja algo verdadeiro na teologia que não seja verdadeiro na filosofia, resulta, na mudança do todo correto, que haja algo verdadeiro para o sujeito existente que seja falso para a abstração; do mesmo modo, é eticamente verdadeiro que o ser puro é uma fantasia e que, ao sujeito existente, resulta proibido esquecer que é um sujeito que existe (KIERKEGAARD, 2008, p. 307).

Sendo a realidade substancialmente o indivíduo, "a subjetividade é a verdade; a subjetividade é a realidade" (Id., p. 345), pois a subjetividade é o lócus da experiência, daquela experiência irredutivel à qualquer possivel classificação. Compreender o significado de sujeito e de experiência em Kierkegaard implica, portanto, o desvelamento de uma consequência do movimento do espírito hegeliano supostamente sistemático, a saber: a pretensa superação da subjetividade.

O homem é algo concreto, temporário, em um devir constante, luta entre o finito e o infinito, entre o temporal e o eterno. Dessa maneira de ser existente e livre, o quem sou eu como ser que existe em uma realidade concreta, encontra-se submerso em angústia, pois, dirá Kierkegaard,

[a] angústia é a realidade da liberdade enquanto possibilidade para a possibilidade (Angest er Frihedens Virkelighed som Mulighed for Muligheden) [...] tem aqui o mesmo significado que melancolia, num momento bem posterior, quando a liberdade, depois de ter percorrido as formas imperfeitas de sua história, deve chegar a ser ela mesma, no sentido mais profundo da palavra (KIERKEGAARD, 2017 , p. 25).

A angústia surge, portanto, frente à possibilidade de escolher ou mesmo de não escolher. $\mathrm{O}$ não escolher paralisa a possibilidade antes de sê-la possivel. Não obstante, escolher pode gerar arrependimentos pelo fato de a escolha se tornar demasiadamente equivocada. Neste sentido, "na angústia reside a infinitude egoísta da possibilidade, que não tenta como uma escolha, mas angustia, insinuante, com sua doce ansiedade" (Id., p. 37). A chave de entrada no castelo é: liberdade. "[A] angústia é a vertigem da liberdade, que surge quando o espírito quer estabelecer a sintese, e a liberdade olha para baixo, para sua própria possibilidade, e então agarra a finitude para nela firmar-se" (Ibid., p. 37). Liberdade é a verdadeira essência da existência. Ela está no individuo especifico com quem ele vive na história e que a manifesta através de seus atos.

Se a filosofia hegeliana se ancora na universalidade como uma forma de realização do Espírito absoluto, Kierkegaard vê a subjetividade como uma unidade absoluta. A finitude encerra a experiência humana. Quando nos referimos à experiência ou a existência, nos referimos de maneira mais precisa ao sujeito que tem por objeto sua existência mesma, particular. Aqui Kierkegaard pensa o individuo a partir dos três estádios (Stadier) de existência, quais sejam: i) o estético, ii) o ético e iii) o religioso. Cada um dos estádios manifesta a verdade contida implicitamente no estádio anterior, mediante um retorno circular à origem, cujo ponto de partida subjaz a ideia da totalidade do desenvolvido e cujo ponto de chegada confirma o eternamente confirmado. Existencialmente, ao passo de cada escolha, o sujeito vive a angústia da possibilidade (ou mesmo do retorno).

\section{OS ESTÁDIOS DA EXISTÊNCIA}

\section{1 o estético (Don Juan)}


O termo estético é utilizado por Kierkegaard num sentido muito mais amplo que em seu uso habitual. "A estética", diz ele, "é aquilo pelo qual esse homem é, imediatamente [...] O que vive na estética, pela estética, da estética e para a estética que há nele, vive esteticamente" (KIERKEGAARD, 1959, p. 35). Indiferente ao bem e ao mal, o esteta abandona-se à vida imediata e não reflexiva. Vida baseada no lirismo e na imaginação, incorporada principalmente em seu personagem Johannes. Em suas palavras:

[o] esplendor, o divino da estética reside precisamente em se ligar apenas ao que é belo; no seu âmago, ela apenas se ocupa das belas-artes e do belo sexo. Posso deleitar-me e deleitar o meu coração, imaginando o sol da feminilidade dardejando os raios da sua infinita plenitude, disseminando-se numa verdadeira torre de Babel, onde cada uma em particular possui uma pequena parcela de toda a riqueza da feminilidade de modo a fazer dessa parcela o centro harmonioso do resto do seu ser (KIERKEGAARD, 1979, p. 170).

O personagem encarna o estético sob o signo dos prazeres. No estético, o homem não escolhe si-mesmo, não realiza a sintese entre os opostos que o compõem (corpo e alma). Ele faz do tempo, finito, uma totalidade que apenas responde aos sentidos: vive de coletar instantes, ele quer viver eternamente do instante. $\mathrm{O}$ instante constitui como presença total de uma ação absoluta, exercida na transcendência e prolongada no tempo. No instante, a eternidade assume o caráter concreto da existência humana e o devir livre resulta qualificado como história pessoal. Este presente absoluto, que é presença e realidade plenas, expressa, assim, a contemporaneidade do eu consigo mesmo, como o Outro e com os outros. Seu princípio regulador é o desejo. O desejo não está necessariamente associado ao amor físico, mas à carne. $\mathrm{O}$ desejo é o fundamento do estádio estético - Kierkegaard geralmente se refere a Don Juan, que, segundo ele, espiritualiza a carne. Don Juan é a encarnação do desejo. Desejo representado pelo puro prazer em desejar.

Um Barba-Azul mata, na própria noite de núpcias, todas as jovens que amou, mas não tem prazer em matá-las, pelo contrário, o prazer foi tido antes, o que constitui a manifestação material: não é uma crueldade pela crueldade. Um Don Juan sedulas e abandona-as, mas todo o seu prazer reside em as seduzir e não em as abandonar; não se trata pois, de modo algum, dessa crueldade abstrata (Id., p. 174).

Com sugere Valls no pósfácio à edição brasileira do Begrebet Angest ( $O$ conceito de angústia), "Kierkegaard personificava os problemas: sensualidade em Don Juan, dúvida em Fausto, desespero no Judeu errante, fé em Abraão, ser cristão em Paulo" (VALLS, 2017, p. 88). No estádio estético, o pensador dinamarquês apresenta três modos de ser referentes a esse estádio. Cada modo é representado por um personagem literário cuja função não está em descrever "personagens no interior da literatura e nem pretende desenvolver uma análise literária deles. As figuras servem como espelhos que caracterizam determinada realidade de um drama, de uma comédia ou de uma tragédia, já que a existência comporta todos esses aspectos" (ALMEIDA; VALLS, 2007, p. 14). Os personagens, ou melhor, as figuras como espelho que concebem o estádio estético são: i) Don Juan, representando a sensualidade e o estado primitivo do desenvolvimento moral (no Diário do sedutor, Johannes é o pseudônimo no qual Kierkegaard reflete a ideia de Don Juan); ii) Fausto, a dúvida e a suspensão do télos moral; e, por fim, iii) o Judeu errante, Ahasverus, representando o desespero.

$\mathrm{O}$ esteta almeja realizar todas as possibilidades, mas estas não lhe proporcionam mais que uma atualidade transitória. Consequentemente, a busca estética de novidades conduz, em última instância, ao desespero. O momento estético no fundo é ilusório. "Sob o céu da estética tudo é leve, belo, fugitivo..." (KIERKEGAARD, 1979, p. 102). O desespero caracteriza a passagem do estádio estético para o estádio ético. Vale ressaltar que as reflexões acerca do estético são realizadas por Wilhelm (Guilherme), um juiz que representa o estádio ético. O que não é de todo estranho, uma vez que na vida estética o 
indivíduo absorto em si mesmo, não é capaz de desligar-se do eu para refleti-lo. De certo modo, o esteta é um prisioneiro inconsciente de si mesmo, e só com o auxílio do outro é capaz de libertar-se.

\section{2 o ético (Wilhelm)}

No ético, ao contrário da voluptuosidade do estético, o indivíduo escolhe a seriedade da existência. Deixa o panóptico do myself, cujo vigilante é o desejo egoico, para entrar no reino da responsabilidade e do dever. $\mathrm{O}$ casamento surge como simbolo do estádio ético, como a imagem sólida da ética. Enquanto o puro desejo, egoico em seus termos, prefigura o momento estético, o amor ao outro, desejado enquanto alterego, caracteriza o momento ético. Cedo-me a licença de lembrar, aqui, apenas ligeiramente, como modelo de uma figura como espelho do ético, de Romeu e Julieta de Shakespeare. Ao se propor despir de seu próprio nome, renunciando, assim, sua condição de partícipe de uma identidade especifica, Romeu almeja ser para o outro.

Julieta:

- Não você, mas apenas seu nome é meu inimigo. Você continuaria sendo o que é, se acaso não fosse Montéquio. O que é um Montéquio? Não é mão, nem pé, nem braço ou rosto, nem parte alguma do corpo de um homem: seja outro nome! O que há num simples nome? O que chamamos rosa não cheiraria igualmente doce em outro nome? Assim Romeu, se não tivesse o nome de Romeu, conservaria a querida perfeição que é dele, sem o título. Romeu, jogue fora o seu Montéquio, que não é parte de você mesmo, e fique comigo, inteira!

\section{Romeu:}

- Peguei você pela palavra! Dá-me o nome de Amor, que ficarei de novo batizado, e nunca mais serei Romeu (SHAKESPEARE, 1997, 43-44).

O excerto acima, a meu ver - abstraindo seus exageros - é exemplar para representarmos o estádio ético kierkegaardiano. A subjetividade ética se define como afirmação absoluta do eu pelo eu-mesmo, i.e., pela moção de sua liberdade. Ainda que o esteta mantenha sua subjetividade na abstração de uma idealidade e possibilidade meramente formais, o ético afirma a sua ideia e sua possibilidade como a realidade efetiva de um si-mesmo finito e infinito concomitantemente (sintese entre o mundo e o eu). Deste modo, ele se torna um sujeito concreto, cujo transcorrer histórico se torna temporal e cuja exterioridade fática se converte em sua própria intimidade. O ético é, portanto, a afirmação do eu pelo eu mesmo, e o eu é, assim, o absoluto como resultado de um processo que volta sobre si mesmo. Porque "cada passo em direção ao ideal é um passo atrás" (Every step toward the ideal is a step backward) (KIERKEGAARD, 2015, NB21: 65-67, p. 43), a subjetividade ética retorna à origem.

\section{3 o religioso (Abraão)}

A partir do exposto até aqui, cabe perguntar se na existência ética, o indivíduo é capaz de realizar-se mediante o cumprimento do dever (tomado num sentido de geral). Isso porque Kierkegaard pensa a categoria de indivíduo a partir de limites estabelecidos pela sociedade, o que inevitavelmente resulta numa contraposição entre o singular e o universal. Neste sentido, o conflito entre a universalidade e a interioridade da subjetividade é consequente, ou seja, o homem, não anulando a sua subjetividade, terá que conviver com as exigências de adequação às leis universais. Vê-se, assim, o surgimento de uma crise entre o homem e o mundo. 
Tomado como ser imediato, sensível e psíquico, o Indivíduo é o Indivíduo que tem o seu telos no geral; a sua tarefa moral consiste em exprimir-se constantemente, em despojar-se do seu caráter individual para alcançar a generalidade. Peca o Indivíduo que reivindica a sua individualidade frente ao geral, e não pode reconciliar-se com ele senão reconhecendo-o. De cada vez que o Indivíduo, depois de ter entrado no geral, se sente inclinado a reivindicar a sua individualidade, entra numa crise da qual só poderá libertar-se pela via do arrependimento e abandonando-se, como Indivíduo, no geral (KIERKEGAARD, 1979, p. 230).

Pois bem, se o estádio ético constitui a forma objetiva do absoluto (subjetividade) na qual o sujeito assumiu o mundo e o divino, isso não determina o reconhecimento mais próprio do Absoluto. A partir disso, a subjetividade ética cai em contradição com Deus. A tarefa deste último estádio, o religioso, consiste, enfim, na mediação definitiva entre o individuo com Deus e com o próximo mediante o amor. Ao que parece, Kierkegaard quer com isso dizer que quando a absoluta diferença aparece só o amor a supera num terceiro, capaz de assegurar o círculo triádico da unidade. Para Valls e Almeida,

Se o desespero pode ser a passagem do estético ao ético, a deste para o religioso acontece no arrependimento, categoria anti-hegeliana, pois ocorre no interior de duas liberdades que não permitem mediação, do homem que se reconhece finito e pecador e escolhe saltar nos braços de Deus e do Eterno que acolhe o penitente, conforme a parábola do filho pródigo (ALMEIDA; VALLS, 2007, p. 14).

$\mathrm{O}$ estádio religioso coincide com o grande salto para a fé. A fé é entendida como uma expressão do abandono mais absoluto (Temor e tremor). O homem não é mais fundado em si mesmo (estádio estético), nem em sua comunidade (estádio ético), mas em Deus, que é uma experiência inteiramente diferente de qualquer ideia geral que um filósofo possa se tornar. No estádio religioso, o individuo renuncia o desejo (estético = queda) e o dever (ético $=$ autossuficiência) como prova de sua $f e ́($ religioso $=$ salto). $\mathrm{O}$ religioso substitui o desespero pela esperança, a angústia pela confiança na providência de Deus. Ama a Deus e não quer ofendê-lo (Abraão). Sabe que seu dever absoluto não é obedecer à lei, mas sim obedecer a Deus. O indivíduo torna-se, assim, consciente de sua não autossuficiência e, somente através da fé em Deus, realiza-se plenamente. Contudo, ao optar pela fé, ele não encontra uma confirmação concreta de seus atos na realidade; nesse sentido ele efetua o salto da absurdidade, escolhendo correr o risco da fé que não lhe proporciona certeza objetiva. Porque Deus existe somente para a interioridade da subjetividade. A fé está além da racionalidade, pois, dirá Kierkegaard (X4 A, 356, Vol. 2, p. 264) em um dos seus Diários intitulado $A$ fé e a razão: "a fé não pode ser compreendida; o máximo que se pode chegar é compreender que não se pode compreender. Assim, também por razões Absolutas, nenhuma razão pode ser dada; no máximo, pode haver razões pelas quais não existem razões.

\section{A eSTÉtiCA DE CONTEÚdo COMO HERANÇA MATERIALISTA}

Na posição kierkergaardiana ante o estádio estético, Adorno descobre o núcleo teórico fundamental para uma possível critica ao idealismo: "Kierkegaard se proclama como portador de uma estética material ou de conteúdo frente ao 'formalismo estético"" (GÓMEZ, 1998, p. 49). Basicamente essa é a razão pela qual seu pensamento se torna tão sedutor para os críticos do idealismo que sempre e novamente movem a força do indivíduo, daquele que existe em sua mais crua vida, contra o todo. A tese que Adorno defende em sua Habilitationsschrift é que, apesar de todo empenho em se situar frente à filosofia de Hegel, no pensamento de Kierkegaard persiste um componente fundamentalmente idealista, que aparece em sua teoria do estético e em sua compreensão da subjetividade como interioridade sem objeto (Objektlose Innerlichkeit). 
Embora compartilhe com ele a rejeição à ontologia idealista, é perigosa também, segundo o próprio Adorno, a absolutização da experiência subjetiva, expressa por Kierkegaard na construção do estético.

Pois bem, Adorno começa sua Habilitationsschrift distinguindo três concepções do estético que aparecem na obra de Kierkegaard, articuladas em torno de seu interesse por desenvolver uma espécie teoria material (de conteúdo) da arte distinta do classicismo. São elas: i) que na linguagem cotidiana, estética designa o âmbito do estudo da arte e das obras artisticas; ii) mais importante que esta, é o uso do termo estético como um tipo de atitude ou mesmo esfera, distinta e inferior ao ético e ao religioso, caracterizado pela imediatidade e pela exterioridade pela qual se orienta a subjetividade; iii) o fato de Kierkegaard utilizar o termo estético como meio de comunicação pela qual é possivel ser expressa a interioridade do sujeito em relação ao objeto conhecido. Rastreando a função exercida pelo estádio estético na obra kierkegaardiana, Adorno encontra um conteúdo filosófico concreto que excede o nível de uma filosofia da arte. É devido a isso que ele pretende pôr em manifesto a compreensão do estádio estético, não como um elemento que se refere tão somente à esfera artistica, mas sim como uma categoria do conhecimento, ou melhor, como um modelo de pensamento. Trata-se, portanto, diz Adorno, "da interpretação da obra como um todo; ali tão pouco como em Kierkegaard, estética não se chama meramente teoria da arte e sim, falando de maneira hegeliana, uma posição do pensamento frente à objetividade" (eine Stellung des Gedankens zur Objektivität) (ADORNO, 1962, p. 262). Assim sendo, o conteúdo filosófico encontrado por Adorno refere-se à possibilidade de erigir uma teoria do sujeito, pois, não obstante em seus fins ela se revelar idealista, há, em Kierkegaard, a presença de um conceito paradigmático de subjetividade: uma subjetividade sem objeto.

Importante anotar que o fato de Adorno já apontar para a posição do pensamento frente à objetividade como questão precípua na construção kierkegaardiana do estético é bastante significativo. Ele antecipa, sobremaneira, um dos eixos basilares para a orientação materialista de seu pensamento, de forma mais geral, e sua posição crítica acerca do idealismo e da modernidade filosófica, em particular. Refere-se, portanto, à possibilidade de construir um modelo de pensamento capaz de pensar a relação sujeitoobjeto distinto das apresentadas pelo idealismo, especialmente pela fenomenologia husserliana. Revisar tal relação será uma das fundamentais tarefas da filosofia. Uma revisão que os compreenda "como sedimento[s] da história" (ADORNO, 1977, p. 742) frente à reivindicação de identificação total inerente ao pensamento. Essa tarefa que perpassa sua teoria materialista do conhecimento e da experiência tem seu germe inicial, essa é minha posição aqui, já na Habilitation.

A fim de distanciar-se do formalismo estético e, em última instância, do idealismo hegeliano, a intenção de Kierkegaard é construir, articulada sob a primazia do sujeito, uma estética do conteúdo. Para isso, recusa-se a aceitar na esfera do estético tudo o que não deriva do imediatismo da subjetividade, i.e., de sua interioridade. Esse desejo de se distanciar do formalismo estético e, em particular, da oposição tradicional entre forma e conteúdo, entre sujeito e objeto, é entendido por Adorno como uma tarefa malsucedida. Pois,

[a] correção do formalismo na estética de conteúdo é algo que Kierkegaard só consegue de modo ilusório. Pois, onde quer que a estética se apoie no dualismo de conteúdo e de forma, sem evidenciar, na análise efetuada tanta das formas quanto dos conteúdos, seu recíproco ser-produzido-um-pelo-outro, o primado do princípio formal se imporá necessariamente para a teoria. Kierkegaard agarra-se sem mais àquela dualidade e ao mesmo tempo anuncia seu próprio classicismo (ADORNO, 1962, p. 28).

Com isso, a arte é entendida como uma forma de comunicação (Kommunikation), não do objetivo, mas do próprio sujeito que imprime a forma no objeto. De forma mais precisa: é uma arte como comunicação e não como expressão. É um voltar-se do sujeito para o objeto, privando-o de seu conteúdo e, consequentemente, desprovendo-o de 
qualquer valor interno em detrimento do que é determinado pela subjetividade. A existência do objeto estético é apenas o resultado do imediatismo do sujeito. Portanto, dirá Adorno, "este motivo se volta contra a estética [...] Onde Kierkegaard se agarra a ela, a dualidade de forma e conteúdo conserva seu caráter idealista. A estética de conteúdo torna-se formalista sob o signo da "grandeza" dos objetos" (Id.,1962, p. 32). Por isso, para Adorno, Kierkegaard falha em sua tentativa de superar as teses idealistas.

Ainda que Kierkegaard tenha tentado superar, por meios próprios, o sistema hegeliano, ele acaba reproduzindo alguns pontos idênticos ao próprio Hegel e, por consequência, idêntico aos dos idealistas. Neste sentido, e aqui, a meu ver, reside uma tese importante que torna a leitura de Kierkegaard, por parte de Adorno, é o fato de que o filosofo da interioridade oferece ao frankfurtiano, algumas bases extremamente importantes para definir o componente imanente que determinará suas críticas ao sistema idealista e sua posição frente à possibilidade da atualidade (operacional) da filosofia. As objeções ao idealismo filosófico não se dão por meio de um movimento externo ao próprio idealismo. Pelo contrário, a critica imanente busca, no próprio idealismo, suas insuficiências, ou seja, a partir de sua própria estrutura lógica, identificando nela mesma as contradições que podem levar à sua desintegração. Nas palavras do próprio Adorno:

Na medida em que ela se serve de suas premissas, ele já a possui virtualmente em si; por isso, ele é superior a ela. O idealismo rejeita, contudo, as objeções feitas de fora como pertencentes à filosofia da reflexão, como pré-dialéticas. Todavia, a análise não precisa se demitir em face dessa alternativa. A imanência é a totalidade dessas posições de identidade cujo princípio é aniquilado na crítica imanente. De acordo com as palavras de Marx, seria preciso tocar para o idealismo "a sua própria melodia". O não-idêntico que o determina desde o interior, segundo o critério da identidade, é ao mesmo tempo aquilo que se contrapõe a seu princípio e que ele assegura em vão dominar (ADORNO, 1962, p. 262).

Interessa, então, buscar as causas que levaram o projeto idealista ao fracasso, precisamente a partir do seu modelo dicotômico de sujeito e objeto, algo que é extremamente representativo na filosofia de Kierkegaard. A defesa de uma subjetividade abstrata que se refugia na interioridade, resulta vazia por não haver determinações externas atuando sobre ela. Com isso, ele tenta esboçar uma resposta, não apenas diante da teoria hegeliana do Espírito absoluto, mas também da desintegração ou mesmo na reificação social que ameaçavam o individuo. Na figura do intérieur, i.e., da Objektlose Innerlichkeit, Adorno situa a continuação da filosofia idealista do sujeito que mais tarde chamará de "o engodo da subjetividade constitutiva" (der Trug konsumtiver Subjektivität) (ADORNO, 1966, p. 8) e que aqui aparece como um exemplo inicial do que significa sua critica materialista ao idealismo.

O cativeiro categorial da consciência individual reproduz o cativeiro real de cada indivíduo. Mesmo o olhar da consciência que descobre aquele cativeiro é determinado pelas formas que ele lhe implantou. No cativeiro em si, poderiam os homens perceber o cativeiro social: impedir tal coisa constituiu e constitui um interesse, capital da conservação do 'status quo'. Por causa deste interesse a filosofia teria de perder seu rumo, com uma necessidade não menor que a daquelas mesmas formas. Tão ideológico já era o idealismo, antes mesmo de se ter disposto a glorificar o mundo como ideia absoluta. A compensação primitiva implica que já a realidade, elevada à condição de produto de um sujeito presumidamente livre, é, por sua vez, justificada como livre (ADORNO, 1977, p. 750).

Esse refúgio no interior, como defendia Kierkegaard, longe de representar uma defesa do sujeito ou uma libertação das formas de dominio a que ele está sujeito, supõe, na verdade, a inversão definitiva de sua função crítica e o desaparecimento do verdadeiro potencial de resistência. De acordo com Safatle, ratificando a leitura adorniana, "a interioridade - kierkegaardiana - era apenas uma construção burguesa 
abstrata que visava substancializar a impossibilidade de o sujeito moderno reconhecer-se em uma objetividade reificada" (SAFATLE, 2012, p. 169, grifos do autor): o rentier. Quando Kierkegaard supõe encontrar a saida à pressão da objetividade no confinamento de sua individualidade, ele acaba repetindo, sem querer, o mesmo modelo idealista da subjetividade constitutiva. Ao julgar ser possivel eliminar a mediação dialética, portanto objetiva entre sujeito e objeto, e através disso ser factível a superação da paralisia e da reificação, para Adorno, isso resulta num grande erro. Isso porque, na realidade, o movimento mesmo de eliminar a mediação, acaba por produzir um tipo de paralisia ainda mais premente, qual seja, uma subjetividade reduzida a mera tautologia. Que isso significa? Significa que nesse modelo de subjetividade, os componentes materiais e objetivos que a compõe, são subtraídos, e, com isso, sua capacidade de resistência.

A fillosofia idealista se funda na imagem de um sujeito constituída em si mesma (unidade da apercepção transcendental) e livre de determinações empíricas. No entanto, ao operar como constituidora da objetividade, cuja determinação é dada no ato mesmo do sujeito da constituição, a filosofia idealista se revela antinômica desde os seus alicerces. Isso significa dizer que quanto maior for a tentativa de se livrar da objetividade do objeto, afastando-o, e quanto maior for o desejo da imediatidade pura, menos sujeito há. Na hipóstase do sujeito puro, dissolve-se o sujeito - no sentido mais concreto do termo. A separação entre sujeito e objeto, torna-se, em termos adornianos,

ideologia, exatamente sua forma habitual, assim que é fixada sem mediação. O espírito usurpa então o lugar do absolutamente subsistente em si, que ele não é: na pretensão de sua independência anuncia-se o senhoril. Uma vez radicalmente separado do objeto, o sujeito já reduz este a si; o sujeito devora o objeto ao esquecer o quanto ele mesmo é objeto (ADORNO, 1977, p. 742).

Ao que nos parece, o problema em questão é justamente este: a filosofia da identidade, sob o signo do senhoril do eu, que nada mais é que um necessário falsosenhorio, serve à imagem de uma sociedade reconciliada no momento em que o eu-nãose-percebe-objeto de dominação. A imediatidade não permite mediação, transforma-se em couraça mítica, em ideologia. O conceito de "interioridade" kierkegaardiano reproduz, ainda que precipitadamente, a ideologia da filosofia idealista ao cometer o mais desastroso desentendimento, qual seja, não permitir a mediação enquanto mediação dialética.

\section{CONSIDERAÇÕES FINAIS}

$\mathrm{O}$ erro que Adorno atribui à Kierkegaard foi de ter eliminado o momento hegeliano da mediação, interpretando-o como termo médio, colocando, em seu lugar, uma subjetividade isolada e absoluta. Ele falha em superar o sistema da identidade, "nele, Hegel se virou para dentro, e Kierkegaard alcança melhor a realidade lá onde se mantém fiel à dialética histórica de Hegel [...] Ele mesmo só a concebe no esquema da interioridade (Inwendigkeit)" (ADORNO, 1962, p. 49). O intérieur kierkegaardiano é tão verdadeiro, ou melhor, tão-falso, como o todo hegeliano. Os elementos objetivos são negados por uma consciência que se entende apenas enquanto interioridade: a primeira, sem objeto; a segunda, nega de forma determinada o objeto a fim de superá-lo. Assim sendo, no esforço de articular e dominar o conteúdo externo à consciência é a própria subjetividade quem acaba se dissolvendo em algo universal. Adorno vê nessa negação o momento de sacrifício e de renúncia do espírito, que ele interpreta, em última análise, como um momento de dissolução imanente do sistema idealista:

[...] como, para ele, o espírito do indivíduo permanece não só o protótipo de todo espírito, mas também da própria natureza que não se apresenta senão no "espírito": assim também o sacrifício, última categoria à qual ele se eleva e, ao mesmo tempo, categoria da destruição do natural, é para ele sacrifício do espírito. Com a mais 
extrema tensão de que o idealismo formador de sistemas ainda era capaz, ele consumou esse sacrifício não só para a totalidade sistemática, mas também para todos os fenômenos que caem sob o sistema (Id., 1962, p. 152).

O momento da desintegração imanente da lógica idealista é articulado, então, com base nos conceitos de "dominio" (Herrschaft) e "sacrifício" (Opfer). Importante anotar que esses conceitos desempenharão um papel fundamental na Dialética do Esclarecimento. A identidade requerida através de sua absolutização, não equivale apenas à aniquilação do objeto, mas também a do próprio sujeito - característica da perda da experiência e do próprio pensamento. Aniquilar a natureza a fim de que o eu possa se afirmar, no distanciamento e opressão da natureza externa, tende a reprodução do mesmo mecanismo de violência. A tese segundo a qual a absolutização do espírito sobre a natureza do sistema idealista - repetida aqui pelo filósofo dinamarquês - será uma constante no trabalho de Adorno. Isso é expresso nas seguintes linhas:

[...] o poder sobre a vida natural acaba sendo dado unicamente para sua anulação no espírito, e não para a redenção. Mas a destruição da vida natural, que parte da estátua do comendador, é compreendida corretamente como fantasmagórica. Pois aqui não é só a vida natural que vem a ser destruída pelo espírito: o próprio espírito é vida natural destruída e presa à mitologia. Por isso, o espírito não conhece a esperança e, na doutrina kierkegaardiana da fé, o paradoxo desfigura até mesmo a esperança, reduzindo-a a pura destruição da natureza pelo espírito (Ibid., p. 155).

No entanto, e aqui reside um aspecto fundamental que deve ser destacado, Adorno quer mostrar um momento de verdade nessa concepção de subjetividade e, por extensão, na mesma noção idealista de sujeito, porque "ao estatuir-se a consciência da existência [Dasein] condicionada, não suficientemente dedutivel a partir de si mesma, como a contradição suprema de seu idealismo, ele se converte em crítico do sistema" (ADORNO, 1962, p. 152). A mitologização do espírito se dá no esquecimento da dimensão material que o determina em detrimento de uma imersão à interioridade. Por outro lado, o mítico representa, sobremaneira, um protesto do múltiplo, do diverso na natureza contra a unidade lógica que é também identificada com o princípio dominante do espírito. No duplo significado do termo mítico, ele encontra o momento critico que representa a filosofia de Kierkegaard contra a filosofia da identidade, porque, dirá Adorno,

Kierkegaard rompeu as cadeias da filosofia da identidade; e de forma exemplar, posto que o fez de modo imanente e não pela colocação arbitrária, de fora para dentro, de uma posição oposta à de Hegel. No conceito kierkegaardiano de sujeito, como no de existência, repercute aquela realidade não idêntica que a concepção do sujeito puro como espírito no idealismo escamoteia. Neste sentido, Kierkegaard, que difamava a mediação, acentua uma mediação central mais fortemente que Hegel, que decerto a conhecia bem: a do Eu pelo não Eu, a do sujeito constituinte mediante aquilo que, conforme o esquema idealista, dever ter sido, constituído só por ele (Ibid., p. 250-251).

Kierkegaard será, deste modo, uma figura que desempenhará um papel precípuo em sua viragem à "primazia do objeto". O sujeito absoluto, preso em sua interioridade, e sua expressão idealista apresentam, ao mesmo tempo, um componente binário: falsidade e verdade se imbricam dialeticamente. A consciência resulta falsa quando esquece sua dimensão material e lhe é atribuída características que, na realidade, foram subtraídas do social. Mas, precisamente em virtude dessa subtração, um momento de verdade reside no sujeito idealista, pois fornece um relato da real influência que os processos sociais e materiais exercem sobre os indivíduos na sociedade de troca. Ao confirmar a prioridade do objeto, o sujeito idealista se torna verdadeiro. E isso, ele argumenta, já está no existencialismo kierkegaardiano, sendo "uma metafísica do sujeito absoluto que 
regrediu nominalisticamente a indivíduo, e ataque contundente à ideologia do sistema do lucro" (ADORNO, 1962, p. 252).

O componente de verdade que Adorno encontra na figura kierkegaardiana da interioridade pode ser considerado, a meu ver, como uma expressão precoce de uma critica materialista e imanente à filosofia da identidade, uma vez que abre caminho para

102 a não-identidade que, desde dentro, consegue dinamizar (e dinamitizar) as reivindicações de um sujeito puro entendido como espírito. $\mathrm{O}$ trabalho da critica é, justamente, o de confirmar o engodo que é o mito do sujeito autônomo e indeterminado; ou, em outras palavras, somente se a imagem idealista da subjetividade em si for invertida e as contradições por ela geradas forem ex-postas, no horizonte vê-se, auraticamente, a possibilidade da transformação. Esses momentos especificos de seu materialismo são direcionados para uma evocação das relações de domínio social que pairam sobre os individuos e que, enfim, impedem sua completa emancipação.

\section{REFERÊNCIAS}

ADORNO, Theodor W. Kierkegaard: Konstruktion des Ästhetischen. Frankfurt am Main: Suhrkamp, 1962.

ADORNO, Theodor W. Negative Dialektik. Frankfurt am Main: Suhrkamp, 1966.

ADORNO, Theodor W. Zu Subjekt und Objekt. In: ADORNO, Theodor W. Kulturkritik und Gesellschaft: Prismen. Ohne Leitbild. Gesammelte Schriften, Bd. 10.II. Frankfurt am Main: Suhrkamp, 1977.

ALMEIDA, Jorge M.; VALLS, Álvaro L. M. Kierkegaard. Rio de Janeiro: Jorge Zahar, 2007.

BUSSIUS, Júlia. Meu caro Teddie: correspondência entre Kracauer e Adorno (1923 - 1966). Novos estudos CEBRAP, São Paulo, n. 85, 2009.

GÓMEZ, Vicente. El pensamiento estético de Theodor W. Adorno. Madrid: Cátedra, 1998.

HEGEL, Friedrich. Fenomenologia do espírito. Tradução de Paulo Meneses, com a colaboração de Karl-Heinz Efken e José Nogueira Machado, SJ. Rio de Janeiro: Ed. Vozes, 2003.

HEGEL, Friedrich. Linhas fundamentais da filosofia do direito, ou, Direito natural e ciência do estado em compêndio. Trad. Paulo Meneses, Agemir Bavaresco, Alfredo Moraes, Danilo Vaz-Curado R. M. Costa, Greice Ane Barbieri e Paulo Roberto Konzen. São Leopoldo, RS: Ed. UNISINOS, 2010.

HYPPOLITE, Jean. Gênese e estrutura da Fenomenologia do Espírito de Hegel. Trad. Sílvio Rosa Filho. Prefácio de Bento Prado Jr. São Paulo: Discurso Editorial, 2003.

Kierkegaard, Søren. O conceito de angústia: uma simples reflexão psicológico-demonstrativa direcionada ao problema dogmático do pecado. Trad. Álvaro Luiz Montenegro Valls. Petrópolis, RJ: Vozes, 2017.

Kierkegaard, Søren. Postscriptum no cientifico y definitivo a migajas. Traduccion y estudio introductorio de Nassim Bravo Jordan; Prologo de Leticia Valadez Hernandez. México: Universidad Ibero americana, 2008.

Kierkegaard, Søren. Ética y estética en la formación de la personalidad. Buenos Aires: Editorial Nova, 1959.

Kierkegaard, Søren. Diário de um sedutor; Temor e tremor; O desespero humano. Traduções de Carlos Grifo, Maria José Marinho, Adolfo Casais Monteiro. São Paulo: Abril Cultural, 1979 (Os pensadores).

Kierkegaard, Søren. Kierkegaard's journals and notebooks. Volume 8, Journals nb21-25. Volume Edited by Niels Jørgen Cappelørn, Alastair Hannay, Bruce H. Kirmmse, David D. Possen, Joel D. S. Rasmussen, and Vanessa Rumble. Princeton University Press: Princeton and Oxford, 2015.

PERIUS, Oneide. A filosofia como exercício: Walter Benjamin e Theodor W. Adorno. PUCRS, 2011. (Tese de Doutorado).

Safatle, Vladimir. Grande Hotel Abismo: por uma reconstrução da teoria do reconhecimento. São Paulo: Editora WMF Martins Fontes, 2012.

SHAKESPEARE, William. Hamlet. Trad. Millôr Fernandes. Porto Alegre: L\&PM, 1997.

VALLS, Álvaro. Posfácio. In: Kierkegaard, Søren. O conceito de angústia: uma simples reflexão psicológico-demonstrativa direcionada ao problema dogmático do pecado hereditário. Trad. Álvaro Luiz Montenegro Valls. Petrópolis, RJ: Vozes; 2017, p. 87-89. 